\section{Sobre as dores e temores do parto: dimensões de uma escuta}

\section{On pains and fear in childbirth: dimensions of listening}

Ana Verônica Rodrigues 1

Arnaldo A. Franco de Siqueira 2

1,2 Departamento de Saúde Materno Infantil. Faculdade de Saúde Pública. Universidade de São Paulo. Av. Dr. Arnaldo, 715. CEP: 01.246-904. São Paulo, SP, Brasil. E-mail: anavero@usp.br

\begin{abstract}
Objectives: to reflect on the possibilities raised by listening to the life-experiences related by parturient women concerning pain on delivery, using empirical data from research carried out in a Maternity ward in the city of São Paulo, Brazil.

Methods: a descriptive study, with a qualitative methodology, based on the theoretical framework of Social Psychology, Psychoanalysis and Linguistics was carried out, by means of semi-structured interviews with parturient women and midwives, in addition to observation of maternity routines.

Results: one of the findings of the analysis, based on established categories (self-referred subjectivity, intersubjectivity, the appropriation of experience), was the importance of accurate interlocution in the course of the parturition process. This process was mentioned by the parturient women as an experience accompanied by a high level of stress, involving pain, fear and anxiety, although these may be mitigated by the support received.

Conclusions: the analysis shed light on the role of interpersonal relationships involving dialogue and physical contact experienced by these women in reducing the stress of childbirth, suggesting that these constitute a valuable and effective resource that should be offered to parturient woman.
\end{abstract}

Key words Parturition, Labor, Obstetric, Pain

\section{Resumo}

Objetivos: desenvolver algumas reflexões sobre os possiveis efeitos benéficos de uma escuta responsiva à verbalização da presença de dor, medos e seus correlatos na cena do parto tomando como base dados empíricos de pesquisa realizada em maternidade situada na cidade de São Paulo, Brasil.

Métodos: estudo descritivo, de metodologia qualitativa, referenciado no quadro teórico da Psicologia Social, Psicanálise e Lingüistica, utilizando entrevistas semi-estruturadas com 20 parturientes e sete doulas e observação de rotinas da maternidade.

Resultados: a análise, apoiada em categorias estabelecidas (subjetividade auto-referida, intersubjetividade, acolhimento, apropriação da experiência) mostrou, entre outros pontos, a importância e a valorização da interlocução qualificada no processo da parturição. Processo esse referido pelas parturientes como experiência de elevado grau de estresse, com vivências de dor, medos e ansiedades, porém mitigados pelo apoio recebido.

Conclusões: a análise permitiu compreender as relações interpessoais como campo de interlocução $e$ acolhimento percebidos pelas mulheres do estudo capazes de produzir efeitos favoráveis sobre as vivências do estresse materno, configurando-se como recurso técnico, qualificado e valioso, oferecido à parturiente.

Palavras-chave Parto, Trabalho de parto, Dor 


\section{Introdução}

As questões que concernem à assistência ao parto refletem o quadro geral das dificuldades observadas na implementação das políticas públicas do setor saúde do país. As adversidades ainda presentes na atenção à saúde materna oriundas das dificuldades de organização do sistema como, por exemplo, altos índices de mortalidade materna, expressivas taxas de cesárea, baixa qualidade do pré-natal, deficitária disponibilidade de leitos de maternidade, constituem-se em problemas relevantes do ponto de vista da saúde pública no Brasil.1-3

Entre os aspectos importantes da assistência obstétrica no Brasil, a incidência de cesárea tem sido discutida por muitos autores como Faúndes e Ceccatti ${ }^{3}$ que, em busca da identificação de fatores que influenciariam tal incidência apontaram, entre outros, aspectos socioculturais destacando-se, nesse âmbito, o medo da dor durante o trabalho de parto e parto; a idéia de lesões anatômicas e fisiológicas que seriam provocadas pelo parto normal e o conceito, largamente difundido, de que o parto vaginal traz riscos para o feto. Tais idéias, segundo esses autores, tornaram-se prevalentes em meio às mulheres parturientes e entre os médicos.

A insuportabilidade imaginada dessa dor, ainda não sentida no caso das nulíparas; a sua memória, já experienciada em muitos casos de multíparas e em ambos os casos, o seu temor podem imprimir ao momento do nascimento algo tão aterrorizante que leva muitas mulheres à opção do parto cirúrgico sem que esse tenha uma clara indicação do ponto de vista obstétrico. ${ }^{3}$

Como poderosos personagens na cena do nascimento, o fenômeno da dor do parto e todo o conjunto de percepções, sensações, temores, sentimentos e emoções ao redor dele inscrevem-se em muitas dimensões da vida de cada mulher: na ordem da subjetividade por referência às esferas afetivoemocional, cognitiva, história de vida; no plano fisiológico, isto é, à esfera somática; no âmbito sociocultural, no que diz respeito ao pertencimento e identificação com os valores e práticas de um dado grupo social e no nível socioinstitucional, por referência ao sistema de saúde e seus provedores aos quais as mulheres têm acesso, como afirma Lowe. 4

Considerada em suas múltiplas dimensões a dor do parto e o imbricado conjunto das questões a ela relacionadas têm sido abordados em estudos como os de Lowe, 4 Hodnett, 5 Hodnett et al.,6 Klaus e Kennel. 7 Através de revisões sistemáticas de investigações realizadas em vários países, esses autores destacaram a importância de distintos fatores que intervêm na experiência do parto e no manejo das dores a ele relacionadas. Tais revisões têm revelado não só a presença mas também a amplitude e as relações que se estabelecem entre esses fatores intervenientes determinando a qualidade da experiência das mulheres nesta situação. ${ }^{4-6}$

Historicamente termos como agonia, medo, provação, terror, sofrimento morte têm sido associados às vivências do trabalho de parto e ao parto, em muitas culturas e grupos sociais. $\mathrm{O}$ acervo dos modos de enfrentamento da dor mostra, por um lado, um grande e variado repertório de conhecimentos, rituais e técnicas disponíveis em culturas diversas e em conformidade com seus contextos históricos. Por outro, pode-se entender que tal patrimônio revela também a busca incessante para a superação da dor e do sofrimento contingentes à existência humana. No entanto, o conhecimento sobre a natureza da dor do parto e o seu manejo apresenta-se, em muitos estudos, sob debate e controvérsias, notadamente no que tange à segurança dos procedimentos e efetividade dos métodos usados. 8

Na história mais recente, isto é, a partir dos anos 1950, o uso de técnicas comportamentais para minorar as dores do parto tornando-o uma experiência mais satisfatória foram largamente disseminadas pelos obstetras Dick-Read e Lamaze e por autores que propunham a psicoprofilaxia do parto utilizando os métodos da corrente reflexológica da Psicologia Experimental.9,10

De acordo com Langer, 9 tais métodos tinham em comum um processo de trabalho prévio com a futura parturiente que consistia no esclarecimento dos processos fisiológicos do parto; treinamento de exercícios para as fases do trabalho de parto; estabelecimento de contato prévio entre a mulher e quem iria atendê-la durante o parto.

Seguindo essas mesmas preocupações e na busca de um parto mais prazeroso, outros obstetras formaram a chamada segunda geração do "Parto sem dor", nos anos 1960, porém identificados com o "espírito libertário" dessa época, como relata Tornquist. 10 Assim, segundo a autora, foram incorporados aos momentos da parturição e nascimento "valores individualistas/libertários", notadamente aqueles relativos à sexualidade da mulher, à presença e acompanhamento do pai em todo o processo, desde a gestação, e à concepção que afirmava o feto e o bebê como sujeitos com sua individualidade.

Tornquist ${ }^{10}$ assinala ainda que obstetras como Fredérick Leboyer, Michel Odent e Moysés Paciornik incorporaram esses ideais em suas experiências com partos e suas obras tiveram ampla difusão no Brasil. Esse percurso histórico, a partir da 
década de 1960 , poderia ser entendido como um antecedente do Movimento pela Humanização do Parto e do Nascimento, cuja emergência, no país, ocorre no final dos anos 1980.10

Para Lowe 4 diferentemente de outras experiências de dor, aguda ou crônica, a dor do parto não é associada com qualquer patologia.

Relativamente aos fatores ambientais, Lowe 4 afirma que eles devem ser reconhecidos como capazes de afetar de tal maneira a experiência da parturiente que um maior e melhor conhecimento de suas relações com a dor do parto pode levar a intervenções que a auxiliem no enfrentamento da dor Assim, uma abrangente noção de ambiente inclui: a comunicação verbal e não-verbal entre as pessoas; a filosofia que orienta os procedimentos e as práticas dos provedores; a qualidade do suporte oferecido e percebido pelas mulheres; o grau de estranhamento com o ambiente e com seus equipamentos, mobiliário, ruídos, iluminação, temperatura, dimensões do espaço e sua adequação para movimentação, deambulação, entre outros aspectos.

No tocante aos fatores psicológicos diversos autores $4,11-13$ assinalaram a importante contribuição da esfera psicológica na dinâmica do trabalho de parto e do parto. Analisando a interferência da ansiedade no aumento da dor durante o trabalho de parto, Lowe 4 refere, como sendo normal, a presença de um certo nível de ansiedade nas mulheres que se encontram nesta situação, e como nocivo, níveis considerados excessivos, uma vez que a ansiedade pode modificar inclusive os mecanismos fisiológicos da dor do parto.

Para Soifer11 e Noronha, 12 os pensamentos e idéias de morte, de aniquilamento, de fragilidade, de desfalecimento tornam-se bastante vívidos e são mais fortes quanto mais se aproxima a hora do parto

Além disso, à presença da dor ou ao temor de senti-la juntam-se uma grande variedade de sentimentos, sensações, pensamentos, emoções que são a um só tempo mobilizados e mobilizadores de um mal-estar que na literatura sobre o tema encontra-se sob a denominação de estresse materno. ${ }^{13}$

Vale também notar que muitos autores, tais como Lowe, ${ }^{4}$ Cooper et al., ${ }^{13}$ e Da Costa et al., ${ }^{14}$ concordam com a plausibilidade da hipótese da interação entre mecanismos psicofisiológicos e neuroendocrinológicos implicados no "estresse materno". Esses autores convergem também na percepção da necessidade de mais pesquisas que possam avaliar melhor o papel das múltiplas variáveis psicossociais e dos parâmetros endocrinológicos atuantes no trabalho de parto. Lowe 4 acrescenta ao rol dessas necessidades o desenvolvimento de pesquisas que possam esclarecer a influência do ambiente institucional e de práticas obstétricas sobre esses processos fisiológicos.

As contribuições até aqui assinaladas permitem colocar em perspectiva a relevância de uma escuta acurada dos aspectos psico-emocionais que emergem em um momento tão especial e específico da vida das mulheres (e dos homens). Assim, é possível pensar em um lugar privilegiado que tal escuta pode ocupar, pois que ela traz consigo potencialidades favoráveis da relação interpessoal na travessia desse momento.

Desse modo, tomando como base os resultados de estudo realizado em 2004 em uma maternidade da cidade de São Paulo, 15 que abordou a dor do parto, bem como algumas possibilidades do seu manejo, o presente artigo objetiva desenvolver algumas reflexões sobre os possíveis efeitos benéficos de uma escuta responsiva à verbalização da presença desses poderosos personagens - dor, medos e seus correlatos - na cena do parto.

Trata-se, pois, de buscar compreender o lugar, o valor e a qualidade da relação interpessoal que se estabelece entre os envolvidos na situação de trabalho de parto e durante o parto.

\section{Métodos}

O estudo, caracterizado como descritivo, valeu-se de metodologia qualitativa, tendo o referencial teórico ancorado na Fenomenologia, notadamente aquelas do campo da Psicanálise, da Psicologia Social e da Lingüística. 16-20 O diálogo entre esses saberes no tocante ao campo das relações interpessoais e ao campo da linguagem, isto é, as noções de sujeito, intersubjetividade, práticas discursivas, entre outras, mostrou-se valioso como espaço articulador dos aspectos recortados da realidade empírica que se pretendeu investigar.

O estudo foi realizado no "Amparo Maternal", uma maternidade da rede Sistema Único de Saúde (SUS) na cidade de São Paulo. A instituição contava, à época do estudo, com 150 leitos de obstetrícia, sendo que, desses, 24 integravam o Centro de Parto Normal (CPN), onde eram realizados exclusivamente partos vaginais conduzidos por obstetrizes. Utilizava diversos recursos e artefatos para auxiliar no trabalho de parto como: banheira de hidromassagem, duchas, bolas, bancos obstétricos. A maternidade adota práticas de "valorização da fisiologia do parto" também chamado de "parto humanizado". Nesse sentido, foi incentivada a implantação, em 2002, do trabalho de suporte à parturiente realizado 
pelos profissionais e por um grupo de voluntárias que receberam treinamento específico para assumir a função de doula - pessoa que oferece acompanhamento contínuo à parturiente, designada e treinada pela instituição de saúde ou pela comunidade. ${ }^{21}$

As informações coletadas foram obtidas através da técnica de entrevista semi-estruturada com parturientes e doulas e da observação livre, direta e participante das interações e dinâmica das rotinas da instituição de ocorrência da pesquisa. Todas as entrevistas guiadas por um roteiro com questões previamente formuladas e questões emergentes foram gra-vadas e transcritas pela pesquisadora e os dados da observação foram registrados como anotações.

Os critérios de definição dos sujeitos do estudo, assim como a sua proporção numérica foram equacionados de acordo com os parâmetros recomendados na literatura concernente à pesquisa social de caráter qualitativo.22-26

No que se refere ao perfil e tamanho da amostra do estudo considerou-se um conjunto de aspectos tal como assinalado por Minayo,22 a saber: prioridade para os sujeitos sociais com o tipo de inserção na situação que se pretende conhecer e neste conjunto homogêneo de sujeitos buscar a diversidade que permita a apreensão de semelhanças e diferenças; previsão de um número suficiente de sujeitos que possibilite a recorrência das informações atentando para aquelas informações que, pela sua singularidade, podem encerrar um potencial explicativo a considerar.

Assim, com base nessas recomendações, foram entrevistadas 20 parturientes que realizaram parto por via vaginal no CPN da maternidade "Amparo Maternal" e sete doulas que prestaram cuidados às parturientes, na modalidade de acompanhamento contínuo, durante o trabalho de parto e no parto, na mesma instituição. As entrevistas foram realizadas no período do puerpério, no intervalo entre 24 e 30 horas a partir do momento do parto.

Os procedimentos para a organização e sistematização dos dados empíricos foram adotados conforme preconizam Miles e Huberman 25 e Mayan. ${ }^{26}$ A observação do material colhido seguiu as recomendações de Minayo 22 e Queiroz ${ }^{24}$ relativamente à análise de conteúdo/análise temática identificando-se unidades de significado no conjunto das falas. A busca de temas significativos através das repetidas leituras do material (corpus) levou à elaboração de uma lista inicial (start list) de tópicos relativos às categorias gerais relacionadas às questões da pesquisa; à sua problemática; à hipótese apresentada; à referência teórica do estudo.
Dessa maneira, foi formulado um quadro geral das categorias para a análise dos dados relativos às parturientes, como segue: subjetividade; intersubjetividade (subjetividade no contexto relacional); acolhimento; apropriação da experiência (aspectos considerados importantes a serem transmitidos a outras parturientes). Foi adotada a definição do termo subjetividade como:

[...] o caráter de todos os fenômenos psíquicos, enquanto fenômenos de consciência isto é, tais que o sujeito os refere a si mesmo e os chama 'meus. (Abbagnano; 1970: 888). 27

O termo acolhimento foi usado para referir o acesso da parturiente a informações/orientações; a opiniões manifestas sobre a experiência vivida com procedimentos utilizados.

Os resultados descritos estão pautados na análise temática do conteúdo das entrevistas com as parturientes em consonância com o quadro de categorias estabelecido. Os registros de observação da pesquisadora foram utilizados na análise, em caráter complementar às informações obtidas nas entrevistas. Foram também consideradas as informações atinentes ao momento posterior ao parto, designado como "apropriação da experiência".

Cabe observar que a análise desenvolvida recaiu sobre o discurso manifesto dos depoimentos isto é, os tópicos referidos às categorias propostas refletiram os termos verbalizados direta e explicitamente pelas participantes.

O projeto de pesquisa do estudo foi aprovado pelo Comitê de Ética da Faculdade de Saúde Pública da Universidade de São Paulo. Em conformidade com as normas as parturientes foram aqui citadas sob nomes fictícios.

\section{Resultados}

Necessário se faz situar algumas características das participantes do estudo. A escolaridade da maior parte do grupo das parturientes entrevistadas apresentou-se em nível de ensino médio incompleto. A faixa etária das mulheres situou-se entre 15 a 36 anos. Relativamente à situação conjugal preponderou a condição de união consensual. Quanto ao número de filhos, foi expressiva a proporção de primíparas (cerca de 70\%). Todas as mulheres realizaram pré-natal nas Unidades Básicas de Saúde do município e o número de consultas oscilou entre 5-8, variando também a idade gestacional do início do acompanhamento pré-natal. O tempo médio de 
duração do trabalho de parto foi entre 11 e 17 horas.

Por indisponibilidade de vagas nas instituições inicialmente procuradas para a realização dos partos a grande maioria das parturientes foi transferida, em ambulância, para a maternidade "Amparo Maternal".

\section{Os dizeres sobre si (subjetividade auto- referida)}

Merece destaque a recorrência da presença da dor nos relatos sobre a experiência do trabalho de parto e parto subjetivamente vivenciada como sofrimento de considerável intensidade.

Em todos os depoimentos as referências qualificaram a dor como intensa, insuportável, traumática, "horrível", "inesquecível". O tempo de duração entre o trabalho de parto até o momento do parto foi considerado como demasiadamente longo, sendo quase unânime a opinião de que a intensidade da dor e a duração do trabalho de parto foram muito além das expectativas. Foram freqüentes as sensações referidas de exaustão, de desfalecimento, de "não agüentar mais", de "não ter mais força", "de não conseguir ter força" no momento expulsivo.

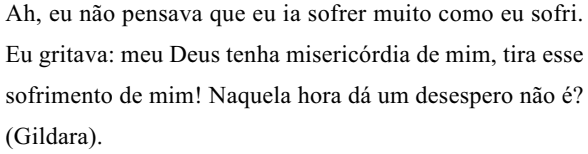

Eu fiquei assustada, com a dor muito forte, nunca tinha sentido aquela dor. Eu fiquei com medo, pensei que ia acontecer alguma coisa comigo. Tipo o quê? Ah sei lá! Dar alguma coisa errada na hora, ele não sair, eu não agüentar a dor, uma coisa assim. (Isabel)

O medo destacou-se com reiterada ocorrência em grande parte dos relatos, tendo sido associado a diferentes motivos, entre os quais, e de modo preponderante, à vivência da idéia da própria morte e/ou do bebê. Para algumas parturientes, o medo relacionado a prováveis agravos à saúde com o bebê foi reportado. O desejo por uma rápida evolução do trabalho de parto foi referido em associação com esta preocupação e com o alívio da dor.

[...] e o medo, medo, o coração disparado! Você tinha medo ...? É, que eu nunca tive um filho. E o medo era de que? De dor. De dor ... (Rosali)
Medo assim de acontecer alguma coisa com a minha filha

[...] queria ver ela nascer logo, saber se ela não tinha

nenhum defeito físico. (Rosemeire)

Sentimentos e sensações como tristeza, depressão, choro, insônia, "nervoso", sentir-se "esquisita", "estranha", ficar com o "coração disparado", impaciência foram termos referidos por algumas das entrevistadas para reportar vivências ocorridas no período próximo ao início do trabalho de parto, ou seja, anterior ao momento da internação. Em algumas entrevistas foram relatadas vivências de solidão, tristeza e choro a partir do momento em tiveram que se separar de pessoas afetivamente significativas, por força do ingresso na instituição.

As observações registraram, com freqüência, verbalizações das parturientes, que estavam em avançado estágio do trabalho de parto, expressando sensações de desfalecimento, de desmaios iminentes, sensações essas acompanhadas de choro, gritos, gemidos, falas de que não iriam conseguir parir, episódios de agitação motora, tremores, alterações na fisionomia, presença de sudorese, esfriamento de mãos e pés.

\section{Os dizeres sobre a presença do outro (intersubjetividade)}

Na quase totalidade dos relatos, para o período do trabalho de parto e parto, observou-se a referência à atenção dispensada às parturientes pelas obstetrizes, outros profissionais e especialmente pelas doulas.

Os cuidados recebidos foram referidos como muito bons e importantes naquele momento de "agonia", de "sofrimento". Foi recorrente a associação, verbalizada, com figuras como "anjo", "mãe", "fada". O medo de ficar só foi também reportado sendo explicitado freqüentemente com pedidos para que as acompanhantes não se afastassem.

Ter sido acompanhada continuamente por alguém foi relatado, com ênfase, pela quase totalidade das mulheres como uma qualidade diferencial do atendimento e a mais apreciada das modalidades nos cuidados que receberam.

Assim, as parturientes relataram que foram influenciadas positivamente pela conversa com a doula. Sensações de segurança, confiança; de relaxamento e calma sobrevindas a partir da presença da doula, também foram preponderantes nos depoimentos.

Me senti bem [...] toda vez que eu precisava sempre tinha alguém para me ajudar aqui. Quando vinha a dor, que eu 
gritava ... porque tem hospital que eles são ignorantes, né? "não grita que é pior!", xingam a gente. Aqui não ... (Kelly)

Ah, tinha uma lá que, sei lá, era meio estressada, meio aborrecida, era mais nova. Mas a outra, mais velha, assim ... era mais carinhosa, porque a gente precisa delas entendeu? Porque a gente sentindo dor, elas estando ali, a gente se sente com alguém. A gente sentindo dor sozinha fica muito ruim. [...] ela me influenciou muito: "vai mãezinha, vai!". Ela era um doce. (Priscila)

Influenciou pra quê?

[...] pra mim ter força, pro nenê nascer. (Priscila)

\section{Discussão}

Uma primeira consideração a ser colocada sobre os resultados encontrados foi a constatação de pontos de conexão e de afastamento no conjunto das falas dos sujeitos participantes, no que diz respeito aos cuidados de saúde prestados durante o trabalho de parto e parto e aos processos comunicacionais ocorridos nesse contexto.

Foi possível observar também que, das narrativas das parturientes sobre a experiência subjetiva, durante o trabalho de parto e parto, emergiram sujeitos constrangidos, em medidas diferentes, pelo sofrimento e acossados pela dor, medo, ansiedade, angústia. Tais processos foram vividos como experiência estressante, de acordo com seus relatos e com as anotações observacionais da pesquisadora.

Caberia destacar ainda que as manifestações exteriores do quadro de tensão psicológica reportado e também descritas nos registros de observação os gestos, o choro, os gritos, suores, agitação motora, alterações na respiração e no semblante pareceram traduzir e consubstanciar o discurso das parturientes sobre o estado emocional em que se encontravam nos momentos do trabalho de parto e parto.

É oportuno citar que tal quadro apresenta-se descrito também em estudos etnográficos, como o de Tornquist 28 realizado no Hospital Universitário da Universidade Federal de Santa Catarina, em Florianópolis. Esse autor pontua a preocupação das parturientes em controlar as emoções relativas à sensação dolorosa para corresponder a uma visão, compartilhada também pelo corpo técnico do hospital, daquilo que seria uma reação adequada a essa dor. Para Tornquist (2003:424):28

[...] enfrentamento adequado da dor supõe a evitação do escândalo, da gritaria, das expressões de desespero, descontrole e descompensação, este último sendo o termo

preferido pela equipe.

Os conteúdos dos depoimentos associados às ansiedades e temores e identificados na análise dos dados, tais como: o perigo de morte iminente, de danos ao corpo, possíveis defeitos físicos do feto, foram também observados em trabalhos de autores como Maldonado e Canella, ${ }^{29}$ Langer ${ }^{9}$, Faúndes e Cecatti, ${ }^{3}$ Soifer, ${ }^{11}$ e Noronha. ${ }^{12}$ Esses autores convergem em chamar a atenção, entre outras coisas, para fatores psicológicos intervenientes que, tensionando mais e mais o processo da parturição, interferem de modo importante na sua evolução. Destacam a importância do apoio psicológico às mulheres, que deveria ser oferecido desde o prénatal.

O medo da dor do parto foi observado, em muitos estudos, como um dos prováveis componentes da ansiedade referida, apresentando alta correlação com as dores reportadas, por muitas mulheres, durante o primeiro estágio do trabalho de parto. 4

Dessa forma, vale pontuar o debate sobre os efeitos que o medo da dor do parto provocariam no comportamento das mulheres. Estudos como o de Osis et al.,30 têm colocado em cheque a visão construída historicamente que o medo da dor do parto representa um marco divisório importante na preferência ou demanda das mulheres pelo parto cirúrgico ou vaginal. Consideram que essa é uma ótica apoiada em "mitos" criados acerca da dor do parto, muito presente na ordem cultural. Para os autores, tais "mitos" teriam sua sustentação nas experiências traumáticas de parto vividas pelas mulheres e narradas, ao longo do tempo, através de gerações.

Importa considerar, assim, as interações de aspectos individuais e socioculturais na construção dessas representações, nos modos de enfrentamento e no processo de ressignificação da experiência da dor. O reconhecimento da lógica sistêmica desses processos poderá levar a um melhor dimensionamento das sensações e sentimentos dos quais falam as mulheres nessa situação e, em decorrência, alargar a compreensão do contexto onde estão inseridos provedores de cuidados e parturientes.

As repetidas declarações das parturientes, de terem sido influenciadas, terem recebido "energia positiva" ou "uma força" das doulas e/ou obstetrizes, para levar a cabo o processo da parturição, parecem indicar a vivência de um processo relacional onde a escuta foi não só valorizada, mas também sentida como processo comunicacional que produziu conse- 
qüências. Assim, a qualidade atribuída aos cuidados permite admitir a impressão de que a presença de interlocutores com as características mencionadas acima produz atos capazes de ter efeitos favoráveis sobre as vivências da parturiente, corroborando resultados também encontrados na literatura sobre o tema referido anteriormente. $4-7$

Nessa mesma perspectiva, tais efeitos poderiam ser encontrados na apreciação retrospectiva das vivências relativas ao parto atual, denominada no presente estudo de "apropriação da experiência". Entre os eventos considerados mais marcantes, além do momento do nascimento dos seus bebês, o suporte recebido e especialmente aquele ligado ao trabalho da doula foi considerado como um dos momentos

\section{Referências}

1. Tanaka ACd'A. Maternidade, dilema entre nascimento e morte. São Paulo: Hucitec; 1995.

2. Diniz CSG. Entre a técnica e os direitos humanos: possibilidades e limites da humanização da assistência ao parto [tese doutorado]. São Paulo: Faculdade de Medicina da Universidade de São Paulo; 2001

3. Faúndes A, Cecatti JGA. Operação cesárea no Brasil incidência, tendências, causas, conseqüências e propostas de ação. Cad Saúde Pública. 1991; 7: 150-73.

4. Lowe NK. The nature of labor pain. Am J Obstet Gynecol. 2002; 186 (Suppl 5): 16-24.

5. Hodnett ED. Pain and women's satisfaction with the experience of childbirth: a systematic review. Am J Obstet Gynecol. 2002; 186 (Suppl): 160-72.

6. Hodnett ED, Gates S, Hofmeyr GJ, Sakala C. Continous support for women during childbirth. Cochrane Database Syst Rev. 2003; (3): CD003766.

7. Klaus MH, Kennell JH. The doula: in essential ingredient of childbirth rediscovered. Acta Paediatr. 1997; 86: 1034-6.

8. Caton D, Corry M, Frigoletto FD, Hopkins DP, Lieberman E, Mayberry L. The nature and management of labor pain: executive summary. Am J Obstet Gynecol. 2002; 186 (Suppl 5): 1-15.

9. Langer M. Maternidade e sexo. Porto Alegre: Artes Médicas; 1986.

10. Tornquist CS. Armadilhas da nova era: natureza e maternidade no ideário da humanização do parto. Est Feministas. 2002; 10: 484-91.

11. Soifer R. Psicologia da gravidez, parto e puerpério. Porto Alegre: Artes Médicas; 1992.

12. Noronha D. Gravidez: situação de crise. Rio de Janeiro: Revinter; 1997.

13. Copper R, Goldenberg RL, Das A, Elder N, Swain M, Norman G. The preterm prediction study: maternal stress is associated with spontaneous preterm birth at less than thirty-five week's gestation. Am J Obstet Gynecol. 1996; 175: 1286-91. mais significativos denotando as repercussões emocionais benéficas dessa modalidade de interação.

Desse modo, os resultados encontrados permitiram compreender a relevância das relações interpessoais no aparato de procedimentos médicos e não médicos, farmacológicos e não farmacológicos presentes no processo da parturição. E que essas relações interpessoais, nos moldes do acompanhamento contínuo, foram percebidas como capazes de produzir efeitos favoráveis sobre as vivências do estresse materno, configurando-se, assim, como recurso equivalente àqueles prescritos como tecnologia apropriada no campo dos cuidados prestados à parturiente.
14. Da Costa D, Dritsa M, Larouche J, Brender W. Psychosocial predictors of labor/delivery complications and infant birth weight: a prospective multivariate study. Psychosom Obstet Gynecol. 2000; 21: 137-48.

15. Rodrigues AV. O suporte à parturiente: a dimensão interpessoal no contexto da assistência ao parto [tese doutorado]. São Paulo: Faculdade de Saúde Pública da Universidade de São Paulo; 2004.

16. Balint M. O médico, seu paciente e a doença. Rio de Janeiro: Atheneu; 1988.

17. Balint M. Psicanális e prática médica. In: Missenard, A. A experiência Balint: história e atualidade. São Paulo: Casa do Psicólogo; 1994.

18. Winnicott DW. A experiência da mãe-bebê de mutualidade. In: Winnicott DW. Explorações psicanalíticas. Porte Alegre: Artes Médicas; 1994. p. 195-202

19. Barros AEB, Oliveira ES. Linguagem, subjetividade e ideal de sujeito nas classes trabalhadoras: configurações e dilemas. In: Jacó-Vilela AM, Cerezzo AC, Rodrigues HBC, organizadores. Clio-psyché: paradigmas. Rio de Janeiro: Relume Dumará; 2003. p. 403-420.

20. Brandão HHN. Introdução à análise do discurso Campinas: Ed. UNICAMP; 2004.

21. Brasil. Ministério da Saúde. Secretaria de Políticas de Saúde. Área Técnica de Saúde da Mulher. Parto, aborto e puerpério: assistência humanizada à mulher. Brasília, DF; 2001.

22. Minayo CSM. O desafio do conhecimento: pesquisa qualitativa em saúde. São Paulo: Hucitec; 1994.

23. Michelat G. Sobre a utilização da entrevista não-diretiva em sociologia. In: Thiollent MJM Crítica metodológica, investigação social \& enquete operária. São Paulo: Polis; 1987. p.191-211.

24. Queiroz MIP. Variações sobre a técnica de gravador no registro da informação viva. São Paulo: T. A. Queiroz; 1991.

25. Miles MB, Huberman AM. Qualitative data analysis. London: Sage; 1994. 
26. Mayan MJ. An introduction to qualitative methods: a training module for student and professionals. Canada: International Institute Qualitative Methodology; 2001.

27. Abbagnano N. Dicionário de filosofia. São Paulo: Mestre Jou; 1970

28. Tornquist CS. Paradoxos da humanização em uma maternidade no Brasil. Cad Saúde Pública. 2003; 19 (Supl 2) 419-27.

Recebido em 5 de outubro de 2006

Versão final apresentada em 20 de março de 2008

Aprovado em 9 de abril de 2008
29. Maldonado MT, Canella P. A relação médico-cliente em ginecologia e obstetrícia. Rio de Janeiro; Atheneu; 1981.

30. Osis MJMD, Pádua KS, Duarte GA, Souza TR, Faúndes A. The opinion of Brazilian women regarding vaginal labor and cesarean section. Int $\mathrm{J}$ Gynecol Obstetr. 2001; 75 (Suppl 1): 59-66 